\title{
The genus Sialis Latreille, 1802 (Megaloptera: Sialidae) in Palaearctic China, with description of a new species
}

\author{
Xingyue Liu \& Ding Yang*
}

Liu, X. \& Yang, D. 2006: The genus Sialis Latreille, 1802 (Megaloptera: Sialidae) in Palaearctic China, with description of a new species. - Entomol. Fennica 17: 394-399.

The species of the genus Sialis from Palaearctic China are revised. Three species are described, including Sialis henanensis sp. n. A key to the males of the species of Sialis from Palaearctic China is presented.

X. Liu \& D. Yang (*corresponding author), Department of Entomology, China Agricultural University, Beijing 100094, China

Received 8 November 2005, accepted 20 January 2006

\section{Introduction}

The megalopteran genus Sialis Latreille, 1802 is the largest genus in the family Sialidae, with 54 described species and subspecies, which are predominantly distributed in the Holarctic Region. The adult is characterized by broad wings with the costal region distinctly dilated before the middle, and branched $\mathrm{R}_{2+3}$ and $\mathrm{R}_{4+5}$. The adult genitalia are highly modified.

The early revisionary works of Weele (1910), Klingstedt (1932a, b), and Ross (1937) were mostly focused on the European and Nearctic Sialis. More recent revisions on Sialis include, Meinander (1962), Aspöck et al. (1980, 2001), Vshivkova (1979, 1985), Hayashi \& Suda (1995, 1997), and Liu \& Yang (2006).

Currently, there are 22 valid recent species and subspecies of Sialis from the Palaearctic Region, with 12 species from the Western Palaearctic Region (Aspöck et al. 2001) and 10 species and subspecies from the Russian Far East, China and Japan. Due to its large size, Palaearctic China generally shares many species with other Palae- arctic areas (Zhang 1999). However, the fauna of Sialis from Palaearctic China is very poorly known, with only two species $(S$. sibirica McLachlan and $S$. longidens Klingstedt) respectively recorded by Yang (1980) and Hayashi \& Suda (1995), while there are five Sialis species from Oriental China (Liu \& Yang 2006).

In this study a new species of Sialis from Palaearctic China is recorded and described. Sialis sibirica and S. longidens are re-described and reillustrated based on specimens collected from China in order to compare them to populations outside of China. A key to the males of these three species is also given. Specimens for the present study are deposited in the Entomological $\mathrm{Mu}-$ seum of China Agricultural University (CAU), Beijing; Institute of Zoology, Chinese Academy of Science (IZCAS), Beijing; and the Shanghai Entomological Museum, Chinese Academy of Science, (SEMCAS), Shanghai. All type specimens are pinned except the holotype of Sialis henanensis sp. n., which is preserved in alcohol. The terminology of the adult genitalia generally follows Contreras-Ramos (2004). 


\section{Systematic part}

\subsection{Sialis Latreille, 1802}

Sialis Latreille, 1802: 290. Type species: Hemerobius lutarius Linnaeus, 1758: 550, by monotypy.

General characters. Alderflies of small-size (forewing length 9-20 mm). Body blackish, sometimes with head and prothorax orange. Head subquadrate, with compound eyes less prominent; vertex usually with elevated pale marks. Prothorax large and rectangular, about 2.5 times wider than long; meso- and metathorax shorter than prothorax. Wings somewhat shortened, with the costal region distinctly dilated before the middle, $R_{2+3}$ and $R_{4+5}$ with two or more branches.

\subsection{Key to males of Sialis from Palaearctic China}

1. Ninth gonostylus nearly semicircular in lateral view, about 1.5 times as long as ninth tergum; tenth sternum extremely small and simple

sibirica McLachlan, 1872

- Ninth gonostylus subquadrate in lateral view, as long as ninth tergum; tenth sternum large, with proximal portion expanded laterally 2

2. Tenth tergum short, as long as $1 / 2$ of width of ninth tergum, dorsally narrowed in lateral view; tenth sternum short, with median portion expanded laterally henanensissp. n.

- Tenth tergum long, as long as 2/3 of width of ninth tergum, not narrowed dorsally in lateral view; tenth sternum elongate, with median portion not expanded

longidens Klingstedt, 1932

\subsection{Sialis henanensis sp. n. (Figs. 1a, 2)}

Material examined. Holotype $\delta^{\top}:$ CHINA: Henan Province, Luanchuan, Longyuwan, $33^{\circ} 47^{\prime} \mathrm{N}$, 111³6'E, 21.V.1999, leg. I. Sivec (CAU).

Diagnosis. Tenth tergum short, as long as $1 / 2$ of width of ninth tergum, dorsally narrowed in lateral view; tenth sternum much shorter than tenth tergum, with proximal and median portion expanded laterally.
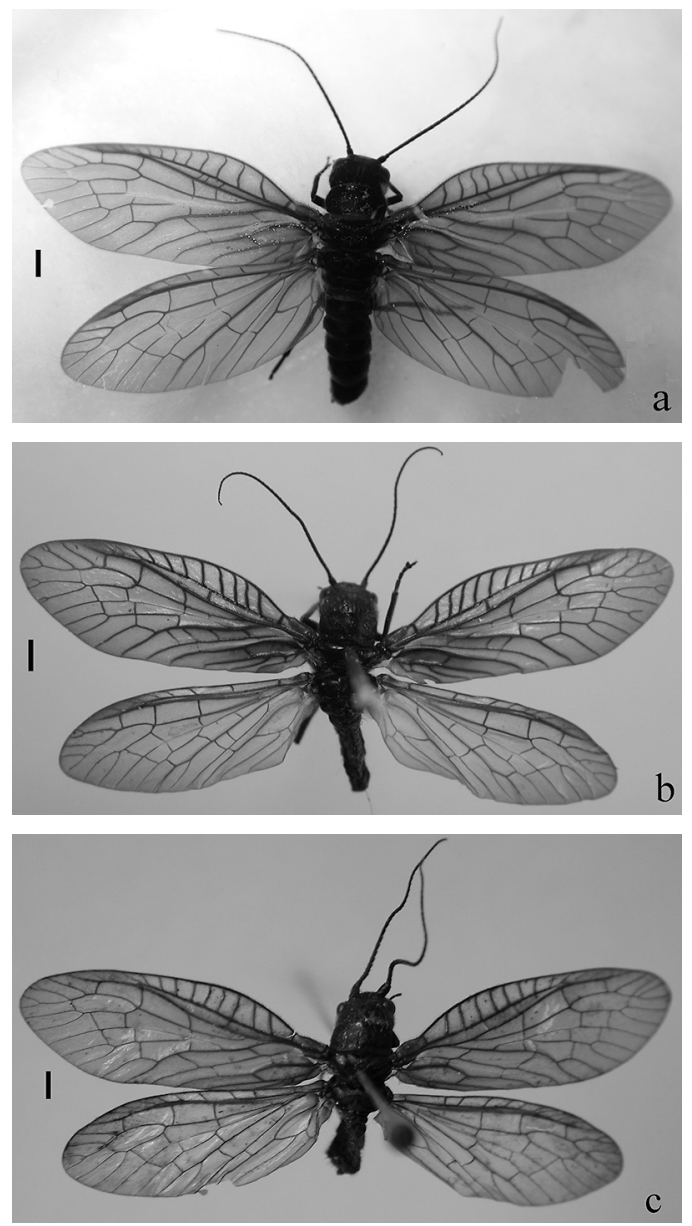

Fig. 1. Species of Sialis from Palaearctic China. - a. S. henanensis sp. n., holotype male. - b. S. longidens Klingstedt, male. - c. S. sibirica McLachlan, male. Scale lines: $1.0 \mathrm{~mm}$.

Description. Male. Body length about $12 \mathrm{~mm}$; forewing length about $12 \mathrm{~mm}$, hind wing length about $11 \mathrm{~mm}$. Head black, vertex with many yellowish brown elevated marks; antenna and compound eye dark brown. Thorax black, legs dark brown. Wings pale brown, hind wings much paler than forewings; veins dark brown. Abdomen black. Tenth tergum short, as long as $1 / 2$ of width of ninth tergum, dorsally narrowed in lateral view (Fig. 2a). Tenth sternum small, unguiform, much shorter than tenth tergum; in caudal view (Fig. 2b) proximal portion and median portion expanded laterally, respectively forming pair of slender lobes, with median lobes slightly shorter and wider; distal half broad with tip strongly nar- 




Fig. 2. Sialis henanensis sp. n., male. - a. Genitalia, lateral view. $-b$. Tenth tergum and tenth sternum, caudal view. - c. Genitalia, ventral view. Scale lines: $0.5 \mathrm{~mm}$. $(\mathrm{t} 9$, ninth tergum; $\mathrm{s} 9$, ninth sternum; g9, ninth gonostylus; $\mathrm{t} 10$, tenth tergum; $\mathbf{s} 10$, tenth sternum; pl, proximal lobe; $\mathrm{ml}$, median lobe). rowed. Ninth sternum narrow, arcuate, in ventral view with lateral portions somewhat narrowed (Fig. 2c). Ninth gonostylus broad; in lateral view (Fig. 2a) subquadrate, with dorsal distal corner dorsally produced; in ventral view (Fig. 2c) subtrapezoidal with triangular tip.

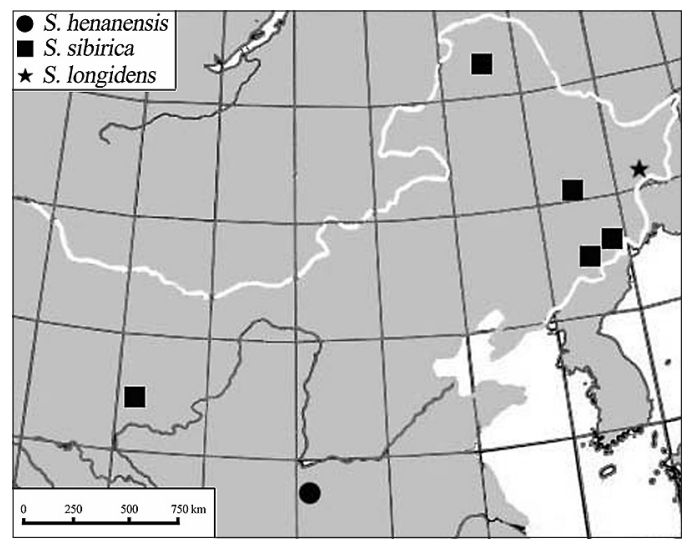

Fig. 3. Distribution map of the Sialis species from Palaearctic China.
Female. Unknown.

Remarks. The new species appears to be closely related to Sialis sinensis Banks in having a similar tenth sternum with its proximal and median portion expanded laterally into two pairs of lobes, but can be separated from $S$. sinensis by the short tenth tergum and the tenth sternum with the median lobes shorter than the proximal lobes. In $S$. sinensis, the tenth tergum is long, and the median lobes are longer than the proximal lobes (Hayashi \& Suda 1995).

Etymology. The name 'henanensis' refers to the type locality of the new species.

Distribution. China (Henan) (Fig. 3).

\subsection{Sialis longidens Klingstedt, 1932 (Figs. 1b, 4)}

Sialis longidens Klingstedt, 1932: 1.

Material examined. CHINA: Heilongjiang

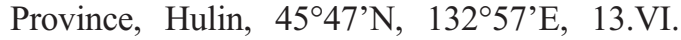
1971, 2 ○ึ (IZCAS). 
Fig. 4. Sialis longidens Klingstedt, male. - a. Genitalia, lateral view. $-b$. Tenth tergum and tenth sternum, caudal view. c. - Genitalia, ventral view. Scale lines: 0.5 $\mathrm{mm}$.


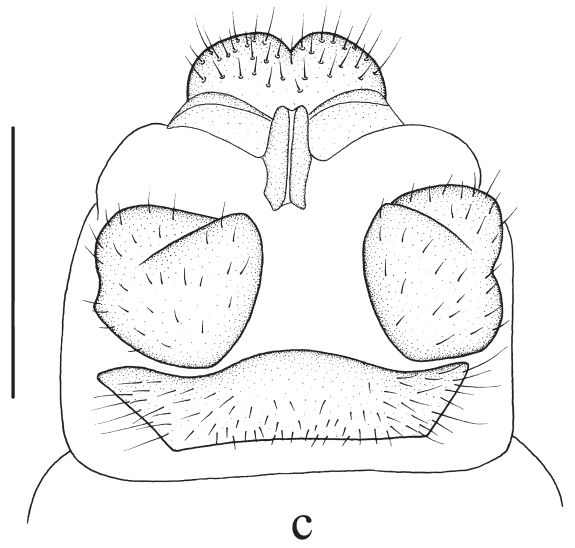

C
Diagnosis. Tenth tergum as long as $2 / 3$ of width of ninth tergum, subquadrate in lateral view; tenth sternum elongate with proximal portion pterygoidly expanded; ninth gonostylus subquadrate with ventroposterior corner angulately prominent.

Description of Chinese male (earlier description of this species can be found in Klingstedt 1932a, Vishivkova 1979, Hayashi \& Suda 1995). Body length 10-11 mm; forewing length 11-12 $\mathrm{mm}$, hind wing length $10-11 \mathrm{~mm}$. Head black, vertex with many brownish elevated marks; antenna and compound eye blackish brown. Thorax blackish brown, legs brown. Wings pale brown, with forewings much darker on basal half; veins brown. Abdomen black. Tenth tergum as long as $2 / 3$ of width of ninth tegum, in lateral view (Fig. 4a) subquadrate with round distal portion. Tenth sternum strongly sclerotized, nearly as long as tenth tergum; proximal half pterygoidly expanded laterally in ventral view (Fig. 4b); distal half long, spine-like, distinctly produced caudally. Ninth sternum narrow, in ventral view with lateral portions somewhat narrowed (Fig. 4c). Ninth gonostylus broad; in lateral view (Fig. 4a) subtrapezoidal, with ventral posterior corner somewhat angulately prominent; in ventral view (Fig. 4c) subquadrate with outer margin slightly concaved at middle.

Remarks. This species was first recorded from China by Hayashi \& Suda (1995), but without any specimens from China as the convincing evidence. In this study, two males were found that clearly proves the existence of this species in China. This species appears to be closely related to Sialis annae Vshivkova in having a similar tenth tergum and pterygoidly expanded tenth sternum, but can be easily separated from $S$. annae by the ninth gonostylus with the ventroposterior corner angulately prominent. In $S$. annae, the ventroposterior corner of the ninth gonostylus is roundly prominent (Vshivkova 1979).

Distribution. China (Heilongjiang) (Fig. 3); Japan, Russia. 

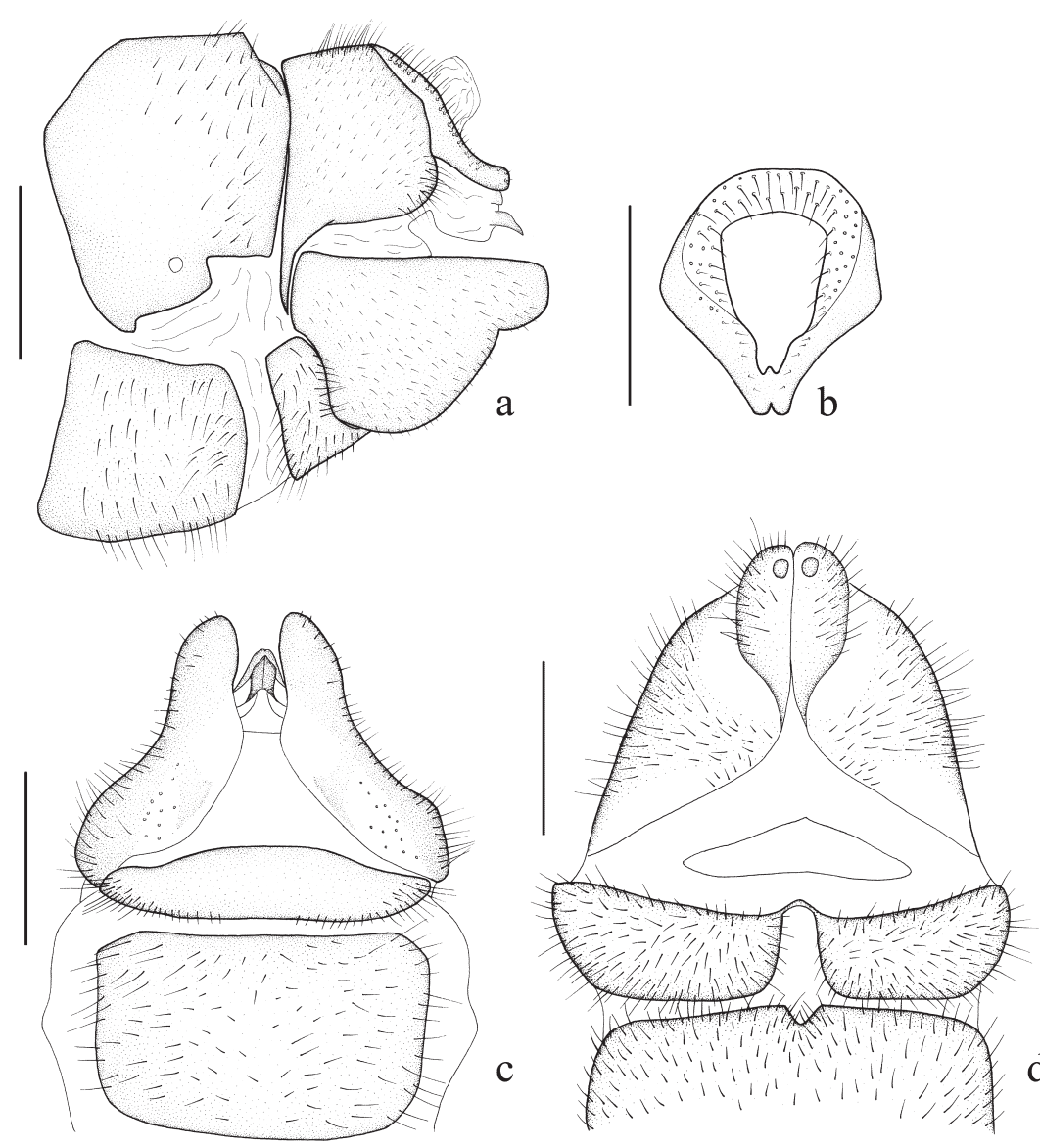

Fig. 5. Sialis sibirica McLachlan. - a. Male genitalia, lateral view. - b. Tenth tergum, caudal view. - c. Male genitalia, ventral view. $-d$.

d Female genitalia, ventral view. Scale lines: 0.5 $\mathrm{mm}$.

\subsection{Sialis sibirica McLachlan, 1872} (Figs. 1c, 5)

Sialis sibirica McLachlan, 1872: 55.

Sialis frequens Okamoto, 1905: 112.

Material examined. CHINA: Heilongjiang Province, Yuquan, $45^{\circ} 23^{\prime} \mathrm{N}, 127^{\circ} 09^{\prime} \mathrm{E}, 15$.VI. 1956, 4 ㅊํ, 3 우우 (CAU); Heilongjiang Province, Talin, $52^{\circ} 01^{\prime} \mathrm{N}, 123^{\circ} 40^{\prime} \mathrm{E}, 5 . \mathrm{VI} .1979,3$ ふ઼ે, leg. C.Y. Cui (SEMCAS); Heilongjiang Province, Huzhong, $52^{\circ} 01^{\prime} \mathrm{N}, 123^{\circ} 40^{\prime} \mathrm{E}, 12$.VI. 1979, 1 ^, leg. C.Y. Cui (SEMCAS); Jilin Province, Manjiang, $41^{\circ} 57^{\prime} \mathrm{N}, 127^{\circ} 37^{\prime} \mathrm{E}, 14 / 28$.VI. 1955, 1 ㅅ, 2 우, leg. Z.Y. Li (IZCAS); Jilin Province, Changbaishan, Toudao, $42^{\circ} 02^{\prime} \mathrm{N}$, $128^{\circ} 08^{\prime}$ E, 5/7.VI.1965, 2 우 (CAU); Jilin Province, Changbaishan, Wenquan, $42^{\circ} 02^{\prime} \mathrm{N}$, $128^{\circ} 08^{\prime} \mathrm{E}, 1 . \mathrm{VII} .1965,1$ ㅇ (CAU); Qinghai Province, Huzhu, $36^{\circ} 51^{\prime} \mathrm{N}, 101^{\circ} 08^{\prime} \mathrm{E}$, 3.VIII. 1975, 1 §ै, leg. Z.G. Xu (CAU).
Diagnosis. Tenth sternum extremely small, divided into paired claws; ninth gonostylus broad, about 1.5 times as long as ninth tergum, nearly semicircular in lateral view with apex distinctly narrowed; female seventh sternum with posterior margin incised medially; female eighth sternum distinctly divided medially.

Description of Chinese specimens (earlier descriptions of this species can be found in Weele 1910, Klingstedt 1932, Vishivkova 1985, Hayashi \& Suda 1995). Male. Body length 8-10 $\mathrm{mm}$; forewing length 11-12 $\mathrm{mm}$, hind wing length 10-11 mm. Head black, vertex with many yellowish brown elevated marks; antenna and compound eye dark brown. Thorax black with legs dark brown. Wings pale brown; veins dark brown. Abdomen black. Tenth tergum (Fig. 5a) narrow, directed ventrally, with tip slightly incised in caudal view (Fig. 5b). Ninth sternum narrow, arcuate, in ventral view with lateral portions 
somewhat narrowed (Fig. 5c). Tenth sternum (Fig. 5a) extremely small, divided into paired claws, connected with ninth tergum and tenth tergum by large membrane. Ninth gonostylus broad; in lateral view (Fig. 5a) nearly semicircular with apex narrowed, subquadrate.

Female. Body length 9-12 mm; forewings $13-15 \mathrm{~mm}$, hindwings $12-13 \mathrm{~mm}$. Seventh sternum (Fig. 5d) medially with one V-shaped posterior incision. Eighth sternum (Fig. 5d) narrow, band-like, distinctly divided at median portion and only connected on posterior margin.

Remarks. This species appears to be somewhat related to Sialis japonica Weele in having a similar ninth gonostylus, but can be easily separated from $S$. japonica by the entirely brownish wings, the caudally produced tenth tergum, and the medially divided female eighth sternum. In $S$. japonica, the basal half of the wings are distinctly darkened, the tenth tergum is less produced, and the female eighth sternum is not divided medially (Hayashi \& Suda 1995).

Distribution. China (Heilongjiang, Jilin, Qinghai) (Fig. 3); Japan, Russia, northern Europe.

Acknowledgements. We are grateful to Mr. Jian Yao (Beijing), Dr. Weinian Zhang and Dr. Xianwei Liu (Shanghai) for loaning many specimens from their collections. We also thank to Dr. Bradley J. Sinclair (Bonn), Dr. Wilfried Wichard (Koeln), Dr. Alexi Popov (Sofia), and an anonymous referee for their kind proofreading the manuscript. We are also much indebted to Professor Chikun Yang (Beijing), Mr. Fasheng Li (Beijing) and Dr. Fumio Hayashi (Tokyo) for their kind help in many ways. This research was supported by the National Natural Science Foundation of China (30370174, 30225009).

\section{References}

Aspöck, H., Aspöck, U. \& Hölzel, H. 1980: Die Neuropteren Europas. Goecke \& Evers, Krefeld.

Aspöck, H., Hölzel, H., Aspöck, U. 2001: Kommentierter Katalog der Neuropterida (Insecta: Raphidioptera, Megaloptera, Neuroptera) der Westpaläarktis. Denisia 2: 1-606.

Contreras-Ramos, A. 2004: Is the family Corydalidae (Neuropterida, Megaloptera) a monophylum? Denisia 13: 135-140.

Hayashi, F. \& Suda, S. 1995: Sialidae (Megaloptera) of Japan. - Aquat. Insects 17: 1-15.

Hayashi, F. \& Suda, S. 1997: A new species of Sialis (Megaloptera: Sialidae) from Japan. - Jpn. J. Entomol. 65: 813-815.

Klingstedt, H. 1932a: Sialis longidens n. sp. aus dem südlichen Zentral-Sibirien. - Mem. Soc. pro Fauna et Flora Fennica 8: 1-3.

Klingstedt, H. 1932b: Neuropterologisches aus Finnland 5. Revision der Guttung Sialis nebst Beschreibung von zwei neuen Arten. - Mem. Soc. pro Fauna et Flora Fennica 8: 3-14.

Liu, X.Y. \& Yang, D. 2006: Revision of the genus Sialis from Oriental China (Megaloptera: Sialidae). Zootaxa 1108: 23-35.

Meinander, M. 1962: The Neuroptera and Mecoptera of eastern Fennosandia. - Fauna Fennica 13: 1-196.

Ross, H.H. 1937: Studies of Nearcic aquatic insects. Bull. Illinois. Nat. Hist. Surv. 21: 57-99.

Vshivkova, T.S. 1979: New data on the systematics and distribution of Megaloptera (Insecta) from the Far East. - In: Levanidov, V.Y., Levanidova, I.M., Chereshnev, I.A. \& Makarchenko, E.A. (eds.), Systematics and Ecology of Fishes from the Continental Waters of the Soviet Far East: 78-85. Akademiya Nauk SSSR, Vladivostok.

Vshivkova, T.S. 1985: Sialidae (Megaloptera) of Europe and Caucasus. - Entomol. Obozr. 64: 146-157.

Weele, H.W. van der 1910: Megaloptera Monographic Revision. - Coll. Zool. Baron Edm. de Selys Longchamps Fasc. 5: 1-93.

Yang, C.K. 1980: Neuroptera. — In: China Academy of Sciences \& Zhejiang Agricultural University (eds.), Iconography of Natural Enemy Insects: 248-268. Science Press, Beijing.

Zhang, Y.Z. 1999: Zoogeography of China. - Science Press, Beijing. 